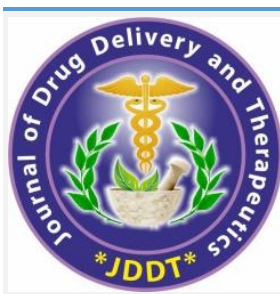

Open Access Full Text Article
Available online on 15.04.2021 at http://jddtonline.info

\section{Journal of Drug Delivery and Therapeutics}

Open Access to Pharmaceutical and Medical Research

(C) 2011-21, publisher and licensee JDDT, This is an Open Access article which permits unrestricted non-commercial use(CC By-NC), provided the original work is properly cited

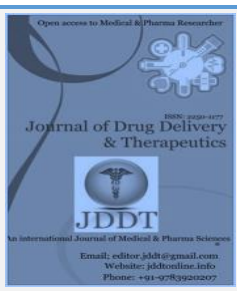

Research Paper

\title{
Use of Antibiotics in Upper Respiratory Tract Infections in Tertiary Care Teaching Hospital of Delhi
}

\author{
Md. Zulqarnain ${ }^{* 1}$, Singh Sanjit ${ }^{1}$, Prasad Abhishek ${ }^{1}$, Abdullah ${ }^{2}$, Palit Tanaya ${ }^{1}$ \\ 1. Assistant Professor, Bihar College of Pharmacy, New Bailey Road, Patna, Bihar 801503, India \\ 2. Research Scientist, Clinical Pharmacology Unit, Sun Pharmaceutical Industries Ltd, New Delhi 110062, India
}

\section{Article Info:}

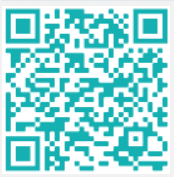

\section{Article History:}

Received 04 Feb 2021

Review Completed 19 March 2021

Accepted 27 March 2021

Available online 15 April 2021

Cite this article as:

Md. Zulqarnain, Singh S, Prasad A, Abdullah, Palit T, Use of Antibiotics in Upper Respiratory Tract Infections in Tertiary Care Teaching Hospital of Delhi, Journal of Drug Delivery and Therapeutics. 2021; 11(2-s):36-40

DOI: http://dx.doi.org/10.22270/jddt.v11i2-s.4793

\section{*Address for Correspondence:}

Md. Zulqarnain, Assistant Professor, Bihar College of Pharmacy, New Bailey Road, Patna, Bihar 801503, India

\section{Abstract}

The aim of this study was to evaluate the prescribing pattern of antibiotics in URTI patients attending the OPD and IPD of HAHC Hospital, a tertiary care teaching hospital of Jamia Hamdard, associated with HIMSR, New Delhi.

URTI account for millions of visits to family physicians each year. Although warranted in some cases, antibiotics are greatly overused. In the present study, an overall antibiotic prescription rate for adult patients with URTI was $45.6 \%$ whereas $54.4 \%$ patients were on non-antibiotic treatment. In our study the antibiotics were prescribed in $10.5 \%$ cases of common cold, $76.47 \%$ cases of pharyngitis, $63.15 \%$ cases of laryngitis, $100 \%$ cases of otitis media and $52.38 \%$ cases of sinusitis. The most commonly prescribed antibiotic was azithromycin which was prescribed collectively in $70.3 \%$ cases of common cold, pharyngitis, laryngitis, and sinusitis. The combination of amoxicillin and clavulanic acid was prescribed in remaining $29.7 \%$ cases suffering from pharyngitis. sinusitis, and otitis media. The antibiotic prescription at Hospital is in line with the ICMR guidelines for URTIs.

We found adverse drug reactions in only $9 \%$ cases receiving azithromycin and combination of amoxicillin and clavulanic acid. The adverse drug reaction reported with azithromycin was diarrhoea, stomach pain, nausea and vomiting whereas only diarrhoea was reported with amoxicillin and clavulanic acid combination. No other unexpected adverse drug reaction was observed in this study.

Keywords: URTI, Antibiotics, Azithromycin and co-morbidities.

\section{INTRODUCTION:}

The rise in antibiotic resistance has become an increasing public health concern worldwide ${ }^{1}$. In developing countries like India, recent hospital and some community based data showed increase in burden of antimicrobial resistance 2 .

The impact of antibiotic resistance includes increased morbidity and mortality from antibiotic-resistant infections 3 , increased socioeconomic burden and greater healthcare costs. 1, 4 Poor antibiotic stewardship is a key driver of antibiotic resistance. ${ }^{5}$ One of the most common causes of visit to physician is Upper respiratory tract infections (URTI). ${ }^{6}$

These infections are often considered to be of little value from a stand point of mortality but these infections are responsible for limited activity and absence from work and school in the general population of nation mainly in a developing country like India, when compared it with other infections. ${ }^{7}$

URTI are commonly caused by the viruses, common viruses which are responsible are rhinovirus, parainfluenza virus, respiratory syncytial virus, influenza virus, coronavirus, coxsackievirus, adenovirus. ${ }^{8}$ URTI are caused by an acute infection which affect the upper respiratory tract including the nose, sinuses, pharynx or larynx and causes common cold, sinusitis, otitis media, tonsillitis, pharyngitis, laryngitis. ${ }^{9}$

As mentioned above, viruses are the most common causes of URTI and thus it requires only symptomatic treatment. To thin the respiratory secretions, it is usually advised to consume plenty of fluids, especially warm fluids, it will not only help in thinning the secretions but also have some soothing effect on the throat. ${ }^{10}$ Large number of over-thecounter (OTC) agents are available in the market in various combinations, none of them have found to be highly effective. ${ }^{11}$ Group of drugs usually preferred are nonsteroidal anti-inflammatory drugs (NSAIDs) for providing symptomatic relief from fever, headache, and malaise; expectorant and antitussives for cough or sore throat; decongestants and antihistamines for runny or stuffy nose. ${ }^{12}$ Many studies suggest that, the antibiotics are not required, but almost $75 \%$ of adults with URTIs are given antibiotics by their consulting doctor. ${ }^{13}$

A substantial proportion of all antibiotics are prescribed in the community ${ }^{14}$, and URTI are one of the commonest 
conditions in the primary care setting for which antibiotic prescriptions have been reported to be high worldwide 15-17

The decision to prescribe antibiotics is intricate and involves number of factors. Apart from clinical factors, others like patient, provider and community characteristics, regulatory practices, cultural influences do play a role. ${ }^{18}$

However, current evidence-based guidelines do not support antibiotic use in the majority of URTI cases 19,20 , as URTIs are frequently of viral etiology $21-23$ are often self-limiting 24 , 25 , and seldom lead to serious complications 26 Inappropriate expectations of antibiotics by patients have been commonly observed in primary healthcare, and is a key factor driving over-prescription of antibiotics in such settings. A study found that physicians are more likely to prescribe antibiotics to patients who desire antibiotics 27 . Furthermore, another study observed that various inappropriate behaviours by patients often pressured physicians to prescribe antibiotics ${ }^{28}$, such as direct request for antibiotics, portraying severity of illness, or volunteering previous positive experience with use of antibiotics and it is also observed in study that primary healthcare physicians over-prescribe antibiotics in order to satisfy their patients 29 . These studies underscore how patient's expectations for antibiotics influence prescriptions by physicians.

By creating awareness and preventing the irrational prescription we can increase the effectiveness of the drugs and thus decreasing the morbidity associated with URTI. The objective of present study is to focus on the trends in the prescription pattern of antibiotics in URTI and to monitor adverse drug reaction associated with the use of these antibiotics.

\section{MATERIALS AND METHOD:}

Study was carried out in the medicine OPD/IPD patient in Hakeem Abdul Hameed (HAHC) Hospital associated with Hamdard Institute of Medical science and Research (HIMSR) Jamia Hamdard. It was a prospective, cross sectional, noninterventional, qualitative drug utilization evaluation of antibiotics utilized in URTI patients. Total 103 URTI patients, including 51 males and 52 females were enrolled according to the inclusion criteria. This research was carried out in accordance with the Basic Principles defined in ICH 'Guidance for good clinical Practice' and the principles enunciated in Declaration of Helsinki (Edinburgh, October 2000).

\section{RESULTS}

A total of 103 patients of URTIs were studied for patient demographics, prescribing pattern and adverse drug reactions.

\section{Demographic Details of the Patients}

\section{Gender Distribution of Patients with URTI}

Among the total of 103 patients, 51 (49.2\%) were male patients with the mean age of 35.25 years \pm 11.26 and 52 $(50.8 \%)$ were female patients with the mean age of 35.19 years \pm 8.96 .

Table 1: Gender Distribution of Patients with URTI

\begin{tabular}{|c|c|c|}
\hline GENDER & No of Patients & Percentage (\%) \\
\hline MALE & 51 & 49.2 \\
\hline FEMALE & 52 & 50.8 \\
\hline TOTAL & 103 & 100 \\
\hline
\end{tabular}

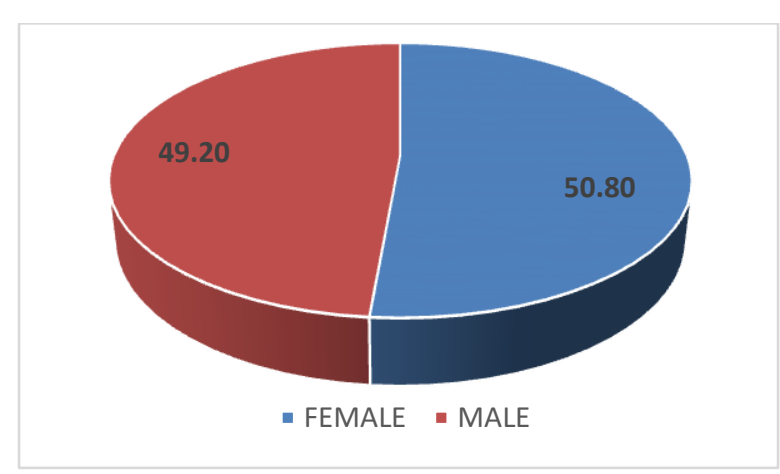

Figure 1: Gender Distribution of Patients with URTI

Distribution of Patients with URTI according to Different Age Group

Among the total of 103 patients enrolled approximately 40 $\%$ of the patients were from the age group of 20-29 years and above, $27 \%$ of patients were in the age group of $30-39$ years, $12 \%$ of patients were in the age group of $40-49$ years, and $15 \%$ of patients were in the age group of 50-59 years. So these four groups contributed almost $94 \%$ of the total patients enrolled. This was followed by the patients of age group $60+$ years that contributed almost $5 \%$ of total patients. The number of elder patients diagnosed with URTI was very small, that is $1 \%$.

Table 2: Distribution of Patients with URTI according to Different Age Group

\begin{tabular}{|c|c|c|c|c|c|c|c|}
\hline \multirow{2}{*}{ S.No. } & \multirow{2}{*}{ Age in Year } & \multicolumn{2}{|c|}{ Male Patients (n=51) } & \multicolumn{2}{c|}{ Female Patients (n=52) } & \multicolumn{2}{c|}{ No. of Patient (n=103) } \\
\cline { 3 - 8 } & & Total & \% & Total & \% & Total & \% \\
\hline 1 & $20-29$ & 22 & 20.9 & 20 & 19.4 & 42 & 28 \\
\hline 2 & $30-39$ & 12 & 11.4 & 16 & 15.2 & 12 & 11.4 \\
\hline 3 & $40-49$ & 06 & 5.7 & 06 & 5.7 & 15 & 14.3 \\
\hline 4 & $50-59$ & 08 & 7.6 & 07 & 6.6 & 06 & 5.7 \\
\hline 5 & $60+$ & 03 & 2.8 & 03 & 2.8 & & \\
\hline
\end{tabular}




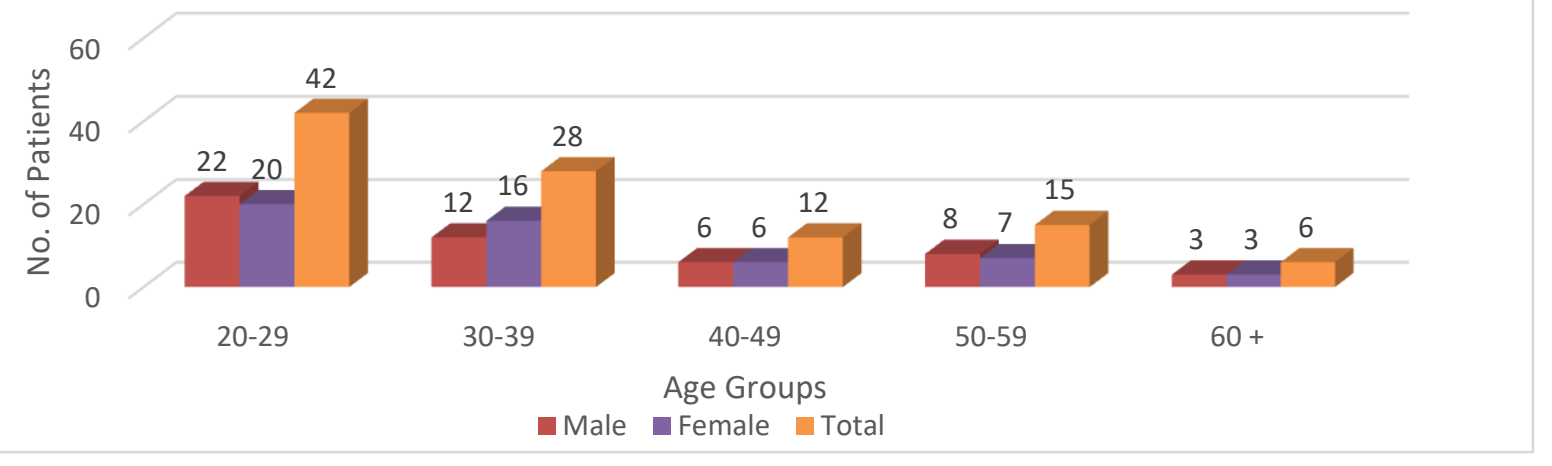

Figure 2: URTI among Different Age Groups

\section{Comorbid Conditions}

Out of total patients enrolled ( $n=103), 18$ patients were observed with co-morbid conditions.

Table 3: Co-morbid conditions of the patients

\begin{tabular}{|l|c|c|}
\hline Co-morbid Conditions & Total (n=18) & Percentage \\
\hline Diabetes & 06 & 33 \\
\hline Multiple Sclerosis & 01 & 5 \\
\hline Thyroid Dysfunction & 07 & 38 \\
\hline Leucoderma & 01 & 5 \\
\hline Tuberculosis & 01 & 5 \\
\hline Diarrhoea & 02 & 11 \\
\hline
\end{tabular}

\section{Drug Utilization}

\section{Drugs Utilized for Treatment of URTI}

Out of 103,47 patients (45.6\%) were on Antibiotic Treatment and 56 patients $(54.5 \%)$ were on Non-
Antibiotics. Among total patients enrolled, highest number of patients were diagnosed with common cold $(n=38)$, followed by Sinusitis $(n=21)$. The number of patients with Pharyngitis $(n=17)$ and Laryngitis $(n=19)$ were almost equal. Least number of patients were diagnosed with Otitis Media ( $n=07)$.

Table 4: Treatment for different types URTI

\begin{tabular}{|c|c|c|c|c|}
\hline Type of URTI & $\begin{array}{c}\text { Number of Patients on } \\
\text { Antibiotic treatment } \\
(\mathbf{4 5 . 6 \% )}\end{array}$ & $\begin{array}{c}\text { Number of patients on Non - } \\
\text { Antibiotic treatment (54.4\%) } \\
(\mathbf{n = 5 6 )}\end{array}$ & $\begin{array}{c}\text { Total } \\
(\mathbf{n = 1 0 3 )}\end{array}$ & $\begin{array}{c}\text { Percentage (\%) } \\
\text { Receiving } \\
\text { Antibiotic }\end{array}$ \\
\hline Common Cold & 04 & 34 & 38 & 10.5 \\
\hline Pharyngitis & 13 & 04 & 17 & 76.47 \\
\hline Laryngitis & 12 & 07 & 19 & 63.15 \\
\hline Otitis media & 07 & 00 & 21 & 100 \\
\hline Sinusitis & 11 & 10 & 52.38 \\
\hline
\end{tabular}

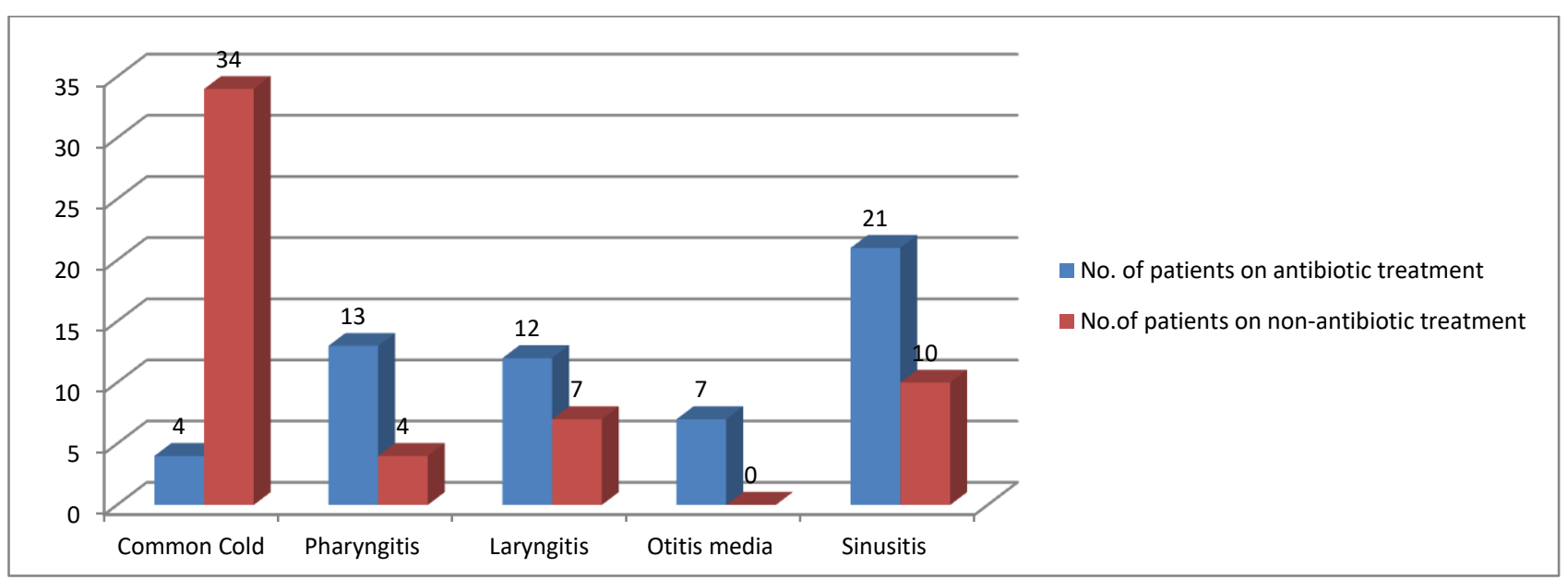

Figure 3: Treatment for different types URTI 


\section{Antibiotics prescribed for different types of URTI}

Antibiotic were prescribed in 47 patients, that is (45.6\%) of the total patient enrolled. The remaining 56 patients that is (54.4\%) patients were on non-Antibiotic treatment. The most commonly prescribed antibiotic throughout the study was found to be Azithromycin (n=33) i.e. $70.3 \%$ of the total prescriptions. This was followed by combination of Amoxicillin and Clavulanic Acid which was prescribed to 14 patients i.e. $29.7 \%$ of the total Antibiotics prescribed.

Table 5: Antibiotics prescribed for different types of URTI

\begin{tabular}{|c|c|c|c|}
\hline \multirow{2}{*}{ Type of URTI } & Antibiotics Prescribed & $\begin{array}{c}\text { Number of } \\
\text { Patients }\end{array}$ & $\begin{array}{c}\text { Total Number of Patients } \\
\text { on Antibiotic }\end{array}$ \\
\hline Common Cold & Azithromycin & 04 & 04 \\
\hline \multirow{2}{*}{ Pharyngitis } & Azithromycin & 09 & 13 \\
\cline { 2 - 4 } & Amoxicillin + Clavulanic Acid & 04 & 12 \\
\hline Laryngitis & Azithromycin & 12 & 07 \\
\hline Otitis Media & Amoxicillin + Clavulanic Acid & 07 & 11 \\
\cline { 2 - 4 } & Amoxicillin + Clavulanic Acid & 03 & 08 \\
\hline
\end{tabular}

Table 6: Antibiotics Prescribed for treatment of URTI

\begin{tabular}{|c|c|c|}
\hline Therapy & Number of Patients & Percentage of Total Antibiotics Prescribed (n=47) \\
\hline Azithromycin & 33 & 70.3 \\
\hline $\begin{array}{c}\text { Combination of Amoxicillin }+ \\
\text { Clavulanic acid }\end{array}$ & 14 & 29.7 \\
\hline
\end{tabular}

\section{Adverse Drug Reactions of Antibiotics}

Out of 103 patients, 10 patients reported adverse drug reactions. Out of which 8 were on Azithromycin and 2 were on Amoxicillin Clavulanic acid.

The adverse drug reactions reported were as follows:

Table 7: Adverse Drug Reactions of Antibiotics

\begin{tabular}{|c|c|c|}
\hline Number of Patients & Antibiotic & Adverse Drug Reaction \\
\hline 6 & Azithromycin & Diarrhea and Loose stools \\
\hline 2 & Azithromycin & Stomach Pain and Nausea, Vomiting \\
\hline 2 & Amoxicillin + Clavulanic Acid & Diarrhea \\
\hline
\end{tabular}

\section{CONCLUSION}

1. The common causes of URTI at HAHC Hospital were Common cold, Sinusitis, followed by Pharyngitis, Laryngitis and Otitis Media.

2. The antibiotics prescription for URTI was found to be relatively low of $45.6 \%$.

3. The most commonly prescribed antibiotic was Azithromycin followed by amoxicillin and clavulanic acid combination

4. The antibiotic prescriptions were in accordance with the clinical practice guidelines of Indian council of medical research.

\section{REFERENCES}

1. Kumar SG et al. Antimicrobial resistance in India: A review. Journal of natural science, biology, and medicine. 2013 Jul; $4(2): 286$.
2. Butler CC, et al. Antibiotic-resistant infections in primary care are symptomatic for longer and increase workload: outcomes for patients with E. coli UTIs. Br J Gen Pact. 2006; 56(530):68692

3. Thabit AK, et al. Antimicrobial resistance: impact on clinical and economic outcomes and the need for new antimicrobials. Expert Opin Pharmacother. 2015; 16(2):159-77.

4. Soothill $\mathrm{G}$, et al. Can we prevent antimicrobial resistance by using antimicrobials better? Pathogens. 2013; 2(2):422-35.

5. Ginde AA, et al. Association between serum 25-hydroxyvitamin D level and upper respiratory tract infection in the third national health and nutrition examination survey. Archives Internal Med. 2009; 169(4):384-90.

6. Finch RG. Epidemiological features and chemotherapy of community-acquired respiratory tract infections. J Antimicrobial Chemo. 1990; 26:53.

7. Hemming VG. Viral respiratory diseases in children: classification, etiology, epidemiology, and risk factors. J Pediatrics. 1994; 124(5):13-6.

8. Manoharan A, Winter J. Tackling upper respiratory tract infections. Practitioner. 2010; 254(1734):25-9. 
9. http://www.clevelandclinicmeded.com/medicalpubs/diseasem anagement/infectiousdisease/upper- respiratory- tractinfection/ Accessed on 1 August 2012.

10. Schroeder K, Fahey T. Over-the-counter medications for acute cough in children and adults in ambulatory settings. Cochrane Database Syst Rev. 2008; 23(1):CD001831.।

11. https://www.signup4.net/Upload/KAIS13A/APR0281E/Deam erURTIsummaryf lyer2007.pdf. Accessed on 12 September 2015.

12. Arroll B, Smith GF. General practitioner management of upper respiratory tract infections: when are antibiotics prescribed? $\mathrm{N}$ Z Med J. 2000; 113(1122):493-6.

13. Wise R, et al. Antimicrobial resistance: is a major threat to public health. BMJ (Br Med J). 1998; 317(7159):609.

14. Goossens H, et al. Outpatient antibiotic use in Europe and association with resistance: a cross-national database study. Lancet. 2005; 365(9459):579-87.

15. McCaig LF, Hughes JM. Trends in antimicrobial drug prescribing among office-based physicians in the United States. JAMA. 1995; 273(3):214-9.

16. Trap B, Hansen E. Treatment of upper respiratory tract infections-a comparative study of dispensing and non-dispensing doctors. J Clin Pharm Ther. 2002; 27(4):289-98.

17. Huang $\mathrm{N}$, et al. Antibiotic prescribing by ambulatory care physicians for adults with nasopharyngitis, URIs, and acute bronchitis in Taiwan:

18. Zoorob R, Sidani MA, Fremont RD, Kihlberg C. Antibiotic use in acute upper respiratory tract infections. Am Fam Physician. 2012; 86(9):817-22.

19. http://www.ncbi.nlm. nih.gov/books/NBK53632/. Accessed 24 Oct 2016.
20. Hong $\mathrm{CY}$, et al. Acute respiratory symptoms in adults in general practice. Fam Pract. 2004; 21(3):317-23.

21. Gageldonk-Lafeber $\mathrm{AB}$, et al. A case-control study of acute respiratory tract infection in general practice patients in The Netherlands. Clin Infect Dis. 2005; 41(4):490-7.

22. Poole PM, Tobin JO. Viral and epidemiological findings in MRC/PHLS surveys of respiratory disease in hospital and general practice. Postgrad Med J. 1973; 49(577):778-87.

23. Gonzales R, et al. Principles of appropriate antibiotic use for treatment of acute respiratory tract infections in adults: background, specific aims, and methods. Ann Emerg Med. 2001; 37(6):690-7.

24. Meropol SB, Localio AR, Metlay JP. Risks and benefits associated with antibiotic use for acute respiratory infections: a cohort study. Ann Fam Med. 2013; 11(2):165-72.

25. Petersen I, et al. Protective effect of antibiotics against serious complications of common respiratory tract infections: retrospective cohort study with the UK General Practice Research Database. BMJ. 2007; 335(7627):982

26. Linder JA, Singer DE. Desire for antibiotics and antibiotic prescribing for adults with upper respiratory tract infections. J Gen Intern Med. 2003; 18(10):795-801.

27. Scott JG, et al. Antibiotic use in acute respiratory infections and the ways patients pressure physicians for a prescription. J Fam Pract. 2001; 50(10):853-8.

28. Lam T, Lam K. What are the non-biomedical reasons which make family doctors over-prescribe antibiotics for upper respiratory tract infection in a mixed private/public Asian setting? J Clin Pharm Ther. 2003; 28(3):197-201.

29. Fendrick AM, et al. The economic burden of non-influenzarelated viral respiratory tract infection in the United States. Archives of internal medicine. 2003 Feb 24; 163(4):487-94 